\title{
АНТРОПОЛОГИЯ ОБРАЗОВАНИЯ
}

\author{
Борис Куприянов
}

10.37492/ETN0.2020.62.4.008

\section{Реконструкция уклада отечественной детской музыкальной школы конца XX - начала XXI вв.}

Автор исследует массовую детскую музыкальную школу в контексте истории зарождения и развития отечественной системы начального музыкального образования, анализируя уклад жизни образовательной организации, его исторический прообраз и образ в современных исследованиях.

Ключевые слова: уклад жизни образовательной организации, антропология образования, история повседневности, школьная повседневность, музыкальная школа, детская школа искусств, советская повседневность.

Детскую музыкальную школу ХXXXI веков следует рассматривать в контексте истории зарождения и развития отечественной системы начального музыкального образования.

Массовое музыкальное образование в нашей стране ведет свою историю со второй половины XIX века, к началу

Куприянов Борис Викторович профессор Департамента педагогики Института педагогики и психологии образования Московского городского педагогического университета, доктор педагогических наук, профессор (Москва),

bvkupriyanov@yandex.ru следующего - двадцатого столетия в Российской империи действовало уже несколько тысяч ${ }^{1}$ частных музыкальных учебных заведений, многие под эгидой «Российского императорского музыкального общества». В первые годы революции «Российское императорское музыкальное об-

${ }^{1}$ Такого числа музыкальных школ удалось достичь только к 1970 гг., конечно, количество обучающихся в школах в начале века было небольшим.

щество» было упразднено, одни музыкально-образовательные учреждения национализированы, другие прекратили свое существование. По мнению историков музыки, «с уничтожением высшего сословия и почти полной ликвидацией среднего в России были утрачены традиции домашнего обучения детей музыке, игравшего значительную роль и в общем музыкальном воспи тании, и в начальном музыкальном образовании» [19, с. 17]. Преобразования в сфере музыкального образования позиционировались советской властью в рамках курса на всеобщую грамотность и демократизацию искусства.

Советский проект музыкального образования (1918$1933)^{2}$ представлял собой переформатирование разнообразных (по уровню, содержанию и форм подготовки) и многочисленных практик обучения музыке. В его рамках было осуществлено разграничение уровней подготовки музыканта (начальной, средней и высшей ступеней образования), необходимость этой меры обсуждалась музыкальной общественностью уже с конца XIX века [19, с. 17].

Разграничение уровней подготовки музыканта состоялось благодаря конференции музыкантов-педагогов, созванной музыкальным отделом Наркомпроса (1919, г. Москва), где и были нормативно оформлены ступени музыкального образования:

«...а) первая ступень спечиального музыкального образова ния, давая начальный курс музыкального образования, явля ется в то же время периодом испытания способностей учаше гося $\kappa$ специальному музыкальному образованию, после которого учашийся либо продолжает свое музыкальное образо-

\footnotetext{
2 Историческая реконструкция советского проекта «Музыкальное образование» может осуществляться на основе изучения работ В.И. Авратинера, Т.Л. Беркмана, В.И. Муцмахера, Н.Г. Дьяченко, П.В. Халабузаря
} и других авторов. 
вание в школе II ступени, либо выбывает из школы, как немогущий стать полезным работником в области музыкального искусства;

б) вторая ступень специального музыкального образования дает законченное профессиональное образование и готовит руководителей для школь I ступени и по музъкальному просвещению (дошкольному, школьному и внешкольному);

в) третья ступень специального музыкального образования завершает музыкальное образование» [19, с. 17].

Постепенно эта трехступенчатая схема стала выглядеть так: I ступень - детская музыкальная школа (музыкальное отделение детской школы искусств); II ступень - среднее специальное образование (музыкальное училище); III ступень - высшее музыкальное образование (музыкально-педагогический факультет педагогического вуза, музыкальный факультет института культуры, консерватория).

В 1930-е гг. первоначальный проект музыкального образования в СССР был дополнен сегментом для одаренных детей, возникли «музыкальные школы-десятилетки» (впоследствии - «средние специальные музыкальные школы», сокращенно ССМШ), которые непосредственно и готовили детей к поступлению в консерваторию [22, с. 31-36]. Этот сценарий музыкального образования предусматривал обучение музыкально одаренных детей по более прямой и короткой траектории. Музыкальные школы-десятилетки (с интернатом) открывались при консерваториях, в образовательном процессе принимали участие консерваторские преподаватели [24, с. 31-36]. По данным О.В. Шестаковой, всего в СССР с 1933 по 1991 г. было открыто 24 средние специальные музыкальные школы (для сравнения, детских музыкальных школ, школ искусств уже в 1978 г. в СССР насчитывалось более 7 тысяч).
Послевоенный период в истории музыкального образования в СССР характеризуется бурным ростом числа детских музыкальных школ. Если в 1960 г. на территории РСФСР функционировала 1001 детская школа искусств, музыкальная и художественная школа, то через десять лет их стало 2756, а к 1990 г. такого рода внешкольных учреждений было уже 5582 [15;16].

Представив инфраструктурные параметры обсуждаемого явления, обратимся к культурному пространству, игравшую существенную роль в жизненном мире советского школьника - ученика детской музыкальной школы, воспользовавшись для этого формулой «уклад детской музыкальной школы».

\section{Уклад жизни образовательной организации}

В зарубежной и отечественной науке немало сделано для понимания того, что называется укладом жизни образовательной организачии. Методологический ключ к разработке этой проблематики дал французский социолог П. Бурдье. Вообще в зарубежной традиции и ряде работ отечественных авторов вместо слова «уклад» используются не менее точные, но более наукообразные словосочетания: «институциональный контекст образования», «скрытое учебное содержание» (Я. Миллер, У. Селлев, И.Д. Фрумин) [20; 21].

Собственно, словосочетание «уклад школьной жизни» в отечественной исследовательской традиции обычно связывают с именем А.Н. Тубельского [12, с. 2]. Однако весьма похожие мысли обнаруживаются у многих отечественных авторов: «духовная физиономия школы» (П.Ф. Каптерев), «дух школы (класса)» (А.С. Макаренко, В.А. Сухомлинский), «быт и жизнедеятельность воспитательной организации» (А.В. Мудрик, М.В. Воропаев, Б.В. Куприянов, М.В. Шакурова), «воспитательная среда образовательного учреждения» 
(И.А. Колесникова, Ю.С. Мануйлов, Л.И. Новикова, Н.Л.Селиванова), «образовательная среда» (В.А. Ясвин), «школьный уклад» (А.А. Остапенко), «уклад школы» (С.Н. Вачкова) и др. Вообще, в отечественной научной традиции с категорией «уклад» работали и историки (Н.И. Костомаров, В.В. Пономарева, Л.Б. Хорошилова), и философы (М.Я. Гефтер, С.А. Никольский, Ю.И. Семенов), и социологи (О.П. Фадеева, В.А. Ядов) [27].

На основе осмысления идей вышеназванных авторов уклад понимается как органическая соииальная система (установившийся порядок) образовательных отноше ний определенного типа (образ жизни), образующая спечифическую общественную форму образования, предназна ченную для соииокультурного воспроизводства. Другими словами, уклад детской музыкальной школы - это:

- способ существования организма, то есть живого явления, живущее (питающееся, болеющее, рождающееся, умирающее), порядок складывается в процессе длительной эволюции отношений, не исключающий отдельные перевороты;

- соединение традиционных форм организации учебной и внеучебной деятельности;

- порядок отношений между учеником и учителем, учителем и родителем, руководителем и учителем и т. д., а также порядок ценностных отношений (к человеку, к природе, к культуре и т. д.),

- образ жизни как социокультурная метафора («школа как храм науки», «школа как мастерская», «школа как община» и т. д.),

- способ воспроизводства личности определенного типа (например: предпринимателя, государственного служащего, социального активного общественника, интеллигента, фермера и т. д.; каждому типу личности соответствует своя форма организации общественной жизни).
Уклад детской музыкальной школы упорядочивает практики участников образовательных отношений (в функциях и действиях), в том числе в символических, рождая конструкцию циклов коллективного существования в пространстве и времени (организация учебного дня, учебной недели, учебного года и т. д.), соединяет учащихся, педагогов и родителей в смыслах и ценностях, в отношениях друг к другу.

В качестве методологической основы для определения специфики уклада детской музыкальной школь весьма адекватными представляются идеи известного французского социолога и культуролога Мишеля Фуко:

- изучение субъекта следует осуществлять таким образом, чтобы исследуемый выступал в качестве результата языковых и общественных практик;

- историческая реконструкция явлений предусматривает их трактовку как порождаемых (конституируемых) социальными практиками, а также дискурсами;

- исследование дискурса (общественной практики существования языка и вещей) может осуществляться не только в историческом или культурном планах, но и в социальном плане как исследование властных, управленческих отношений;

- при исследовании социальных явлений интегративное единство обнаруживаемых в них дискурсов, конституирующих практик и социальных отношений следует именовать диспозитивом [22].

Наши исследования форм социального воспитания в дополнительном образовании детей [7;8], укладов школьной жизни [9], программ летних загородных лагерей [6], позволяют воспользоваться идеей диспозитива как базовой теоретической конструкцией. Отсюда основаниями для обозначения специфики уклада детской музыкальной школы могут служить характери- 
стики, отражающиеся в отношениях между субъектами, культурных практиках и дискурсах:

- мера императивности (с одной стороны, директивность, субординированность, вертикальность отношений, с другой - предоставление возможности субъектам свободно распоряжаться своими правами, допускаются инициатива и самостоятельность, участники получают право урегулировать собственные действия по своему усмотрению, нормы определяют пределы такого усмотрения либо устанавливают процедуры регулирования, участники получают права на выбор образа и пути, допускается экспериментирование);

- мера совместности (в максимальной мере осуществляемая сообща, коллективная жизнедеятельность, публичная - доступная для обозрения, открытая, своего рода коллективное принуждение, в минимальной мере совместная (автономная) - жизнедеятельность, в которой для каждого предусмотрена независимая линия движения, возможно уединение, нет необходимости быть вместе) [6, с. 86-97].

Специфика уклада детской музыкальной школы сочетается с описанием Я. Корчаком, и вслед за ним В.А. Ясвиным и Е.Н. Роготневой, так называемой карьерной среды - направленной «на формирование активной и зависимой личности, которая активно добивается поставленных целей в условиях жесткой конкурентной борьбы согласно общим правилам, развивая в себе качества перфекциониста» [13, с. 49; 28, с. 94] (того, кто стремится к совершенству и устанавливает идеальные стандарты поведения или достижения какой-нибудь цели).

\section{Исторический прообраз уклада детской музыкальной школы}

В своих предыдущих публикациях, обнаруживая в историко-педагогических текстах его следы как устой- чивой культурной традиции, такой уклад мы определяли как «школьный или гимназический». В частности, опираясь на работы Ю.А. Шичалина, можно утверждать, что оформлению структуры и соответствующей аксиологии современное общество обязано Древней Греции [14, с. 42-45]. В Афинах воспитание было направлено на гармоническое и всестороннее развитие духовных и телесных сил юношества. Концепция идеала воспитания человека - калокагатия (греч. kalokagathia, om kalos - прекрасный, agathos - добрый) - предусматривала гармонию внешних достоинств человека и его внутренних, духовно-нравственных основ. Идеал красоты включал единство, гармонию духа и тела, а величина, порядок и симметрия считались символом прекрасного. Поэтому основной путь воспитания предполагал следование канонам идеального, последние были запечатлены в статуях богов и героев, драматических произведениях [6-8].

В Древней Греции следование канонам для приближения к идеалу осуществлялось в рамках гимнастического и мусического воспитания. «Это найдено еще с древнейших времен: для тела - гимнастическое воспитание, а для души - мусическое» (Платон). Гимнастическое воспитание связано прежде всего с обучением свободно и быстро бегать, поскольку бег считался основой физической подготовки. В гимнасиях воспитанники также занимались борьбой, прыжками, метанием диска и копья, плаванием, греблей и игрой в мяч. Мусическое воспитание (от греч. - «мусике», букв. искусство муз) в области литературы, науки, искусства предполагало знакомство с изречениями мудрецов, рассказами о древних подвигах, обучение игре на музыкальных инструментах и хоровому пению. Слушая о наградах и достойных деяниях, юноши стремились подражать им, чтобы потомки впоследствии также их воспевали, вос- 
хищались ими. Ведущими методами мусического и гимнастического воспитания можно назвать соревнование (поддержание духа соперничества), общественное мнение. Демонстрационной площадкой достижений становились Олимпийские и подобные им Пифийские, Истмийские, Немейские игры. В отличие от Олимпийских (чисто атлетических) Пифийские и Истмийские игры включали состязания певцов и музыкантов. Победители игр получали в награду лавровый венок и горшок оливкового масла - символы бессмертной славы для древних греков. Знаменитые поэты посвящали победителям торжественные песни, городские власти ставили мраморные статуи, а историки заносили их имена в анналы.

Для еще одного подтверждения аксиологии соответствующего уклада представляется возможным опереться на замечание М.В. Шакуровой: понятие «школа» в переводе с латинского (schola) - «лестница», «восхождение» - «...такая трактовка подразумевает динамическое развитие ребенка, обретение им своего «Я», восхождение личности к духовно-нравственным ценностям человеческого бытия...» [23, с. 8].

Уклад детской музыкальной школы в современных исследованиях

Для характеристики уклада детских музыкальных школ можно воспользоваться диссертационными исследованиями Б.Е. Булычева, Л.Ю. Калининой, Л.В. Лахмостовой, И.И. Махмутовой, Л.В. Остожьевой, Д.Ю. Рузиева, Ж.А. Сулейменовой, Н.Г. Тапилина, С.А. Шаронова, Э.Э. Эмануэль $[1 ; 4 ; 10 ; 11 ; 18 ; 25]$, peзультатами наших исследований [9].

Соииальной миссией детской музыкальной школы является воспроизводство тех социальных групп, которые сохраняют и воспроизводят культурные образцы, однако противоречивость этой миссии состоит в необходимости осуществлять и воспитание профессиональных музыкантов, и подготовку квалифицированных реципиентов для занятий музыкой в свободное время (их подавляющее большинство в массовой ДМШ).

В педагогическом аспекте миссия разворачивается как ценностная ориентация школьников на эталоны классической культуры, нравственные ценности (трудолюбие, самосовершенствование, дисциплинированность) и развитие музыкальных способностей.

Образование в музыкальной школе осуществляется в соответствии с учебным планом в течение 5-7 лет по ряду учебных дисциплин (основная специальность инструмент, хор, сольфеджио, музыкальная литература и т.д.).

Уклад жизни детской музъкалъной школљ, с одной стороны, представляет собой социокультурный организм детско-взрослой совместности, а с другой - разворачивается в специфические жизненные миры обучающихся и обучающих.

Уклад жизни детской музыкальной школы строится вокруг музыки - искусства, отражающего действительность в звуковых художественных образах, причем для него характерна глубокая дифференциация по специальностям (музыкальные инструменты).

Важной составляющей уклада жизни детской музыкальной школы можно назвать культивирование таких ценностных ориентиров как:

- следование культурному эталону как признанному образцу, которому необходимо следовать;

- целеустремлённость (достижение поставленной цели своими усилиями);

- саморегуляция (нацеленность на преодоление себя, собственных слабостей, необходимость справляться с трудностями, возникающими в процессе деятель- 
ности, перебарывать свои страх, усталость);

- самосовершенствование (целенаправленное развитие себя, собственных способностей);

- стремление к построению карьеры (от итал. carriera бег, жизненный путь, поприще, продвижение в какой-либо сфере деятельности, достижение известности, славы);

- готовность к конкуренции (позднелат. - concurrentia; от concurrere - сталкиваться, соперничество в достижении сходных целей, лучших результатов в определенной сфере деятельности).

Уклад жизни детской музљкальной школь характеризуется цикличностью (цикл обучения игры на музыкальном инструменте (5-7 лет) и годовой цикл освоения образовательной программы).

Уклад жизни детской музыкальной школы отличается преобладанием учебно-репетиционных будней, периодов фестивалей и ситуаций презентации - итоговой оценки результатов (конкурсы). Жизнь детской музыкальной школы протекает в период с сентября по апрель, для фестивалей и спортивных сборов используются периоды школьных каникул. Разнообразие в учебно-тренировочный период обеспечивается, с одной стороны, выходами на представления мастеров в данном виде искусства (посещение конкурсов, концертов), а с другой - мероприятиями клубного (корпоративного) характера (чаепития, посвящение в музыканты). Конкурсы выстраиваются в иерархию: на уровне класса (педагога), на уровне отделения или образовательного учреждения, на муниципальном, региональном, федеральном, международном уровнях и т. д. Подготовка к участию школьников в концертах имеет также довольно длительный характер и связана с многократными репетициями. При этом педагоги, организующие учебный и репетиционный процесс, стараются не пре- вратить их в тренировку по выработке технических навыков или механическое заучивание музыкальных произведений, стремятся не разрушить желание школьника звуками передавать художественный образ.

Через два-три месяца после начала занятий, как правило, организуются показательные выступления для родителей или какой-либо внешней аудитории. Учащиеся детских музыкальных школ организованно, вместе со своими педагогами посещают концерты в филармонии, выступают с отчетными концертами на различных концертных площадках города и т. д.

Соииокультурный механизм образования в детской музыкальной школе предъявление образцов в виде многоуровневой системы ступеней; организация длительных и напряженных упражнений, репетиций, направленных на последовательное овладение уровнями; периодическая аттестация воспитанников в виде участия в различных квалификационных испытаниях, конкурсах (обучающийся получает оценку достигнутых им результатов образования).

При этом для уклада жизни детской музыкальной школы характерна интегрированность в профессиональное сообщество музыкантов, что приводит к возможности перехода наиболее способных школьников к профессиональным занятиям и к сопутствующей профессиональной подготовке. Другими словами, спецификой детской музыкальной школы является выполнение социальной функции - обеспечение региональных и национальных достижений в искусстве. Соответственно, одна из задач детской музыкальной школы осуществлять подготовку наиболее одаренных детей для поступления в соответствующие образовательные учреждения.

Целый ряд музыкальных школ находятся в старинных зданиях. Здесь сами стены задают контекст встречи 
человека с образцами высокой культуры и классического искусства. В специально построенных зданиях помещение может задавать преимущественно ценностно-смысловой план «школы» как таковой. В этом случае решение задач напрямую зависит от того, как оформлено пространство, в котором проходит жизнедеятельность обучающихся. Соответствуют ценностносмысловому плану школы искусств портреты композиторов, художников, работы выпускников, фотографии с концертов, выставок, грамоты и дипломы, полученные детскими коллективами за победу в конкурсах и фестивалях и т. д.

Жизненный мир обучающегося в детской музыкальной школы наполнен повседневным учебным трудом, призванным обеспечить восхождение к вершинам музыкальной культуры. Можно вывести индивидуальную формулу поведения учащегося детской музыкальной школы - достигать успеха в избранных сферах путем напряженного труда и постоянного самосовершенствования, удовлетворяя при этом свое честолюбие, стремление к самоутверждению и самореализации (Н.Б. Стамбулова) [17].

Ежедневные самостоятельные систематические занятия (на уроках и в ходе выполнения домашних заданий) воспринимаются как усилие, преодоление себя, отказ от свободного времени, призванные обеспечить восхождение к вершинам культуры, трансцедентальное переживание ценностного культурного значения смысла, приводящее к личностному росту. Значимыми событиями для учащегося выступают публичные әкзаменационные испытания, требующие высокой саморегуляции.

Преподаватели, стремящиеся добиться ощутимого образовательного результата, ориентируются в своей деятельности на наиболее полное использование физи- ческих и психических данных школьника по отношению к музыкально-исполнительской деятельности, на максимально высокий уровень трудности с учетом зоны ближайшего развития учащихся.

Можно зафиксировать два основных сценария разворачивания обучения в детской музыкальной школе: одаренные дети, у которых меньше затраты времени и усилий на овладение исполнительской деятельностью, и те из учащихся, кто вынужден прилагать значительные силы и время, поэтому испытывают психоэмоциональное напряжение острее, чем их талантливые сверстники.

Для детских музыкальных школ наиболее перспективны в плане достижений школьники, обладающие художественным и академическим типами одаренности (В.С. Юркевич). Художественный тип одаренности (музыкальный) проявляется в высоких достижениях в музыке; музыкальная одаренность может быть частью веера художественных способностей. В случае академического типа одаренности у детей на первый план выходят особые способности именно к обучению - блестяще усваивать, учиться. Особенности познавательной сферы (мышления, памяти, внимания), некоторые особенности их мотивации таковы, что делают учение для них достаточно легким, а в ряде случаев даже приятным. Академический тип одаренности, как указывает B.С. Юркевич, также имеет свои подтипы: есть учащиеся с широкой способностью к обучению (они легко осваивают любую деятельность, проявляют заметные успехи во всех школьных науках), а есть учащиеся, у которых повышенные способности к усвоению проявляются лишь в одной или нескольких близких областях деятельности [26].

Для одаренных детей обучение в детской музыкальной школе выступает как содействие в обретении 
смысла в занятиях музыкой, идентификация с соответствующей социальной группой (музыканты), восприятие занятий музыкой как смысла жизни, то для основной массы занимающихся в ДМШ образование предполагает приобщение школьников к музыкальному наследию, воспитание активных участников художественной самодеятельности, пропагандистов эстетических знаний.

Можно утверждать, что ученик детской музыкальной школы нуждается в индивидуальной помощи со стороны взрослых в ситуациях напряжения сил, открытой конкуренции, переживания победы и поражения, необходимости выстраивать межличностные отношения в музыкальном коллективе исполнителей (ансамбль, оркестр, хор), в самоопределении по отношению к музыкальной деятельности в рамках допрофессиональной и начальной профессиональной подготовки (как в случае успехов и карьерного продвижения, так и в случае неуспеха), в содействии в преодолении кризисов музыкальной карьеры.

Выводы. Реконструкция уклада отечественной детской музыкальной школы конца XX - начала XXI вв. предусматривает рассмотрение процессов возникновения и развития данного типа организаций в предшествующий период, оформление представлений об укладе жизни образовательной организации как модели, выделение культурного аналога школьного уклада - афинской системы воспитания, непосредственное описание уклада жизни детской музыкальной школы в изучаемое время как функционирование социального организма и существование в нем жизненных миров учеников и преподавателей.

\section{Лumepamypa:}

1. Булычев Б.Е. Детская музыкальная школа как современная педагогическая си-

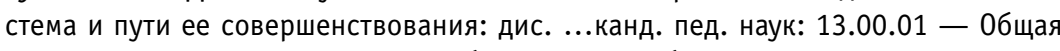
педагогика, история педагогики и образования. Чебоксары, 1998. 147 с.

2. Буторина Н.И. Развитие музыкального интереса учащихся на занятиях сольфеджио: автореф. дис. ... канд. пед. наук: 13.00 .02 - Теория и методика обучения и воспитания (по областям и уровням образования). Екатеринбург, 2002. 21 с.

3. Ильина T.B. Типы образовательных процессов в Уд0 как фактор, определяющий показатели его результативности // Внешкольник. 2001. № 1. С. 7-13.

4. Калинина Л.Ю. Роль литературно-музыкальной композиции в эстетическом воспитании учащихся музыкальных школ: автореф. дис. ... канд. пед. наук: 13.00 .02 Теория и методика обучения и воспитания (по областям и уровням образования) Самара, 2001. 26 с.

5. Куприянов Б.В. Загородный детский лагерь в исторической ретроспективе // Вестник Московского городского педагогического университета. Сер.: «Педагогика и психология». 2018. № 1 (43). С. 86-97.

6. Куприянов Б.В. Программы в учреждении дополнительного образования детей: учебно-методическое пособие. М.: Школьные технологии, 2011. 227 с.

7. Куприянов Б.В. Социальное воспитание учащихся в учреждениях дополнительного образования детей: дис. ... д-ра пед. наук: 13.00 .02 - Теория и методика обучения и воспитания (по областям и уровням образования). Кострома, 2011. 616 с.

8. Куприянов Б.В. Уклады школьной жизни // Народное образование. 2015. № 8 (1451). C. 147-154.

9. Куприянов Б.В., Смирнова И.Э. Детская музыкальная школа второй половинь $\mathrm{XX}$ века (воссоздание результатов деятельности на основе современных воспоминаний) // Непрерывное образование: XXI век. 2020. Вып. 2 (30). С.40-56

10. Лахмостова Л.В. Проблемы совершенствования учебно-воспитательного процесса в сельской детской музыкальной школе на современном этапе: теоретикометодологические аспекты преподавания музыки: на материалах учебной работы сельских детских музыкальных школ Челябинской области: автореф. дис. ... канд. пед. наук: М.: Моск. пед. гос. ун-т, 1997. 20 с.

11. Махмутова И.И. Педагогическое сопровождение выбора профессии педагога-музыканта учащимися сельских детских музыкальных школ Республики Башкортостан: дис. ... канд. пед. наук: 13.00.02 - Теория и методика обучения и воспитания (по областям и уровням образования). Челябинск: Ур. гос. пед. ун-т, 2007. 161 с.

12. Новые ценности образования: Демократическая школа Александра Тубельского. 2012. Вып. № 1 (49). 170 c. URL: http://www.values-edu.ru/wp-content/ uploads/2012/02/nev2012-1.pdf (дата обращения: 10.10.2020)

13. Роготнева Е.Н. Аксиологические границы образовательных систем: дис. ... канд. философ. наук: 09.00.13 - Философия и история религии, философская антропология, философия культуры. Томск: Томский гос. пед. ун-т, 2006. 135 с. 
14. Российская педагогическая энциклопедия: в 2 т. / Гл. ред. В.В. Давыдов. Т. 1: А-М. М.: Большая Российская энциклопедия, 1993. 607 с.

15. Российский статистический ежегодник: Стат. сб. / Редкол.: В.Л. Соколин и др. М.: Гос. ком. Рос. Федерации по статистике, 2000. 725 с.

16. Российский статический ежегодник: Стат. сб./ Госкомстат России. М., 1998. 813 с.

17. Стамбулова Н.Б. Психология спортивной карьеры: учеб. пособие. СПб.: Центр карьеры, 1999. 367 с

18. Сулейменова Ж.А. Взаимодействие общеобразовательной и музыкальной школ в процессе формирования интереса к музыке у младших школьников: автореф. дис. ... канд. пед. наук. Алма-Ата, 1988. 24 с.

19. Федорович Е.Н. История музыкального образования: Учеб. пособие. Екатеринбург: Урал. гос. пед. ун-т, 2003. 110 с.

20. Фрумин И.Д. Скрытое содержание - новая исследовательская программа // Контексты и подтексты образования. М., 2006. Вып. 5-6 (28-29). С. 84-86.

21. Фрумин И.Д. Тайны школы: заметки о контекстах. Красноярск: Краснояр. гос. ун-т, 1999. 255 c.

22. Фуко М. Надзирать и наказывать. Рождение тюрьмы / Пер. с фр. В. Наумова / Под ред. И. Борисовой. М.: Ad Marginem, 2016. 383 с.

23. Шакурова М.В. Социальное воспитание в школе: учеб. пособие для студентов вузов. М.: Академия, 2004. 268 с.

24. Шестакова О.В. Эволюция отечественных средних специальных музыкальных школ для одаренных детей // Вестник Сургутского государственного педагогического университета. 2018. № 1 (52). С. 31-36

25. Эмануэль Э.Э. Эстетическое воспитание учащихся детских музыкальных школ средствами музыки: на материале ДМШ Узбекистана: автореф. дис. ... канд. пед. наук: 13.00.01 - 0бщая педагогика, история педагогики и образования. Ташкент, 1990. 16 c.

26. Юркевич В.С. Одаренный ребенок: иллюзии и реальность: кн. для учителей и родителей. М.: Просвещение, 1996. 128 с

27. Ядов В.А. Стратегия социологического исследования: описание, объяснение, понимание социальной реальности: учебное пособие. М.: Омега-Л, 2012. 567 с.

28. Ясвин В.А. Образовательная среда от моделирования к проектированию. М.: Смысл, 2001. 366 с.

\section{Boris Kupriyanov}

Doctor of Pedagogy, Professor, Department of pedagogy, Institute of Pedagogy and Psychology of Education, Moscow city Pedagogical University, (Moscow),

bvkupriyanov@yandex.ru

\section{Reconstruction of the national children's music school lifestyle of the late XX - early XXI centuries}

The author examines the mass children's music school in the context of the history of the origin and development of the national system of primary music education, analyzing the way of life of the educational organization, its historical prototype and image in modern research.

Keywords: way of life of an educational organization; anthropology of education; history of everyday life; school everyday life; music school; children's art school; Soviet everyday life. 